\title{
Causes of variation in the body composition of growing pigs
}

\section{By Colin T. Whittemore, Edinburgh School of Agriculture, West Mains Road, Edinburgh $E H_{9} 3 \mathfrak{F G}$}

While variation in body composition is most clearly evidenced by changes in the proportion of fat expressed as lipid:protein, there are also independent changes in contents of water, ash and carbohydrate. Water content of the body mass reduces with age and weight such that total body water may be given by the expression 6. I $\mathrm{Pt}^{0.79}$ (Henderson, 1982), where $\mathrm{Pt}$ is the total body protein. The increase in the dry matter of the lean mass in consequence of advancing weight is also shown by the expression PG $(5 \cdot 1-0.009 \mathrm{~W})$ derived from the detailed chemical analysis of growing pigs by Kotarbinska (1969), and used for the prediction of daily lean gains where $P G$ is the daily protein gain and $W$ is the live weight.

At equal fatness, boars have higher concentrations of water in backfat than castrates and lower concentrations of lipid; Wood et al. (1983) found respective proportions for boars and castrates to be 0.16 and 0.11 for water and 0.79 and 0.85 for lipid. Differences in the fatty acid composition of the tissue were slight. The composition of the backfat of gilts and castrates appears to be similar. Young fatty tissue contains a high proportion of water (up to 0.8 after birth) which rapidly falls to about 0.2 at about 3-4 weeks of age (Wood, 1984). With the exception of the consequences of negative fat growth, the water content continues gradually to decline with increasing age and, with increasing quantity of fat, reaches a minimum at about 0.1 water in the fatty carcass tissues. The direct influences of amount and type of dietary fat on amount and type of fat anabolized during growth is well reviewed by Wood (1984). Especially pertinent is the finding that high-level feeding and concomitant rates of fatty tissue growth bring about fatty tissues of lower water content, higher lipid content and lower linoleic acid concentration. Lean boars carrying backfat depths of less than $10 \mathrm{~mm}$ at $\mathbf{P}_{2}$ (site located at $65 \mathrm{~mm}$ from the mid-line at the level of the last rib) when slaughtered at $90 \mathrm{~kg}$ may contain up to 0.25 of the carcass fatty tissue as water; equivalent values for gilts and castrates seem to be about $\geqslant 0.05$ lower (Wood et al. 1985).

Recently catabolized fatty tissue is open to invasion by water (Whittemore et al. 1981). While carcass fatty tissue of suckled pigs contains approximately equal amounts of lipid and water, post-weaning losses from this fraction occur concurrently with water gains. Suckled pigs may gain about $27 \mathrm{~g}$ lipid and $20 \mathrm{~g}$ water daily in the carcass fatty tissues but, within $2 \mathrm{~d}$ of weaning, respective values can be $-75 \mathrm{~g}$ and $+17 \mathrm{~g}$, bringing about a dramatic change in the composition of the fatty tissues. In these circumstances, carcass-fatty-tissue dry matter (CFT DM) is significantly related to the rate of empty-body-weight gain (EBWG); CFT 
$\mathrm{DM}=0.036 \mathrm{EBWG}+50$. The consequential poor relation between rate of live-weight change and extent of fat catabolism has also been noted in lactating mammals.

Causes of variation of the extent of mineralization independent of the strong relation with age and weight is not well documented. Spray \& Widdowson (1950) chose to express mineral content of the body as a proportion of the fat-free body mass, while Kotarbinska (1969) suggests At $=0.19 \mathrm{Pt}$ where At is total body ash. The equivalent coefficient estimated by Henderson (1982) is 0.21 , while the ash content of gain may be estimated as 0.22 PG. Weight of carcass-dissected bone may be approximated from the total ash as $2.5 \mathrm{At}$, or from the total protein mass as $0.50 \mathrm{Pt}$. At and $\mathrm{Pt}$ exclude the bone content of the head. The level of dietary-available mineral may contribute toward the ash in the bone, but the relevance of increased breaking strength to animal productivity is remote. However, the proportion of bone in the carcass is influenced by breed (J. D. Wood, personal communication) such that breeds of the Pietrain and Belgian Landrace types may have a more favourable lean:bone value (6:1 as compared with $5: 1$ for the Large White breed).

Liver carbohydrate is a major energy source in the neonate, when lipid content is extremely low. In later life, variation in body carbohydrate is not significant unless the pig is induced to consume high levels of sugar solution immediately before slaughter, when a short-term liver weight can be doubled.

In pigs there can be important breed variation on body fatness independent of weight, age or nutrition. Prediction of proportions of carcass fat and of carcass lean from depth of subcutaneous backfat at the $\mathrm{P}_{2}$ site seems not to be consistently improved by the inclusion of live weight into the regressions. Recent estimates suggest that percentage lean in the carcass may be predicted from equations of the form $k-n \mathrm{P}_{2}$, where $\mathrm{P}_{2}$ is $\mathrm{mm}$ backfat $65 \mathrm{~mm}$ from the mid-line, $k$ is about 60 and $n$ is about 0.7 . However, such equations suitable for Large White pigs may not be appropriate if the breed in question is of the blocky type which can carry significantly more lean meat at equal fatness. A more universal estimate of percentage lean in the carcass may therefore be of the form $k \mathrm{Pz}^{-n}$, where $n$ is about 0.21 and $k$ indicates the degree of blockiness and ranges between 90 for the Large White breed and roo for the Pietrain type.

\section{Positive growth}

Classical growth analysis such as that proposed by Sir John Hammond presents a view of waves of growth passing through the body as weight and age progesses, concluding with the fattening-out process and tissue deposition in the later maturing body parts. Increasing fatness is proffered by McMeekan (1940) as an exponential function of advancing weight. It now appears that fatness itself, far from being related to age and weight, is instead a direct function of the level of nutrient supply in relation to the level of nutrient need; the latter being defined as the requirements for maintenance plus maximization of potential daily lean tissue growth rate. Modern strains of meat pigs may never contain more than the $15 \circ \mathrm{g}$ 


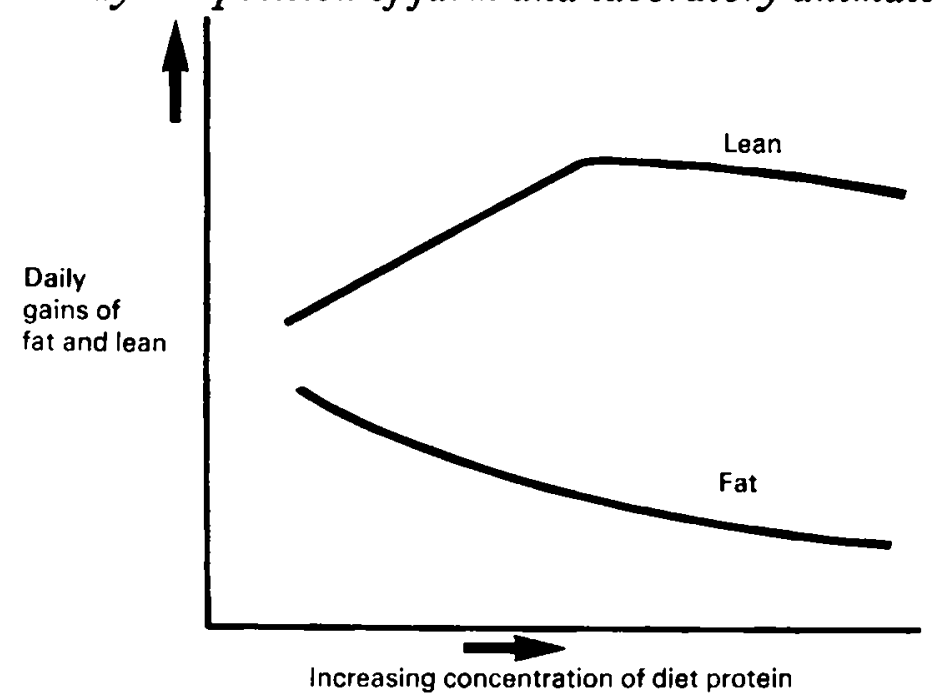

Fig. I. Growth responses of lean and fat to increasing diet protein concentration.

lipid/kg live weight which is evident in extreme youth at 3 weeks of age when sucking. There is little ground for counting age or weight as significant contributors to body fatness in pigs grown for meat. In contrast, animals grown in nutritionally-limiting circumstances may never fatten until maturity of lean body mass is obtained; and in unimproved breeds maturing at small body size the classical sequential process of fattening may be observed. However, with fast-growing improved breeds of larger mature body size, fattening (when and if needed) must be achieved in the course of the immature rapid growth phase, and is dependent on feed intake (voluntary or imposed) being in excess of the need of the animal to meet its aspirations to maximize daily protein accretion.

Improving the diet by increasing the proportion of protein in relation to energy will reduce fatness, as illustrated in Fig. I. If protein supply is inadequate with respect to the needs of maintenance plus protein accretion, dietary energy which is not used for lean tissue growth will be diverted to fat.

As modern improved strains of pigs may reach slaughter weight with less (sometimes considerably less) than $15 \%$ body lipid, then it may be proposed that the balance of fat to lean in the growth should be fairly constant over the whole of the growing period. The idea that, as the slaughter weight is approached, fattening should be induced by means of adjusting the balance of energy to protein is defunct (with the possible exception of breeding-herd replacements); and therefore decreasing the level of dietary protein over the growing period is required only to the small extent needed to cover for the increasing maintenance requirement as the animal grows; this being almost entirely for energy only. The greatest single determinant of variation in the composition of growing pigs is the quantity of food consumed (Fig. 2). The linear response of lean tissue growth to increasing food supply is coupled with a minimum level of fat as is appropriate to normal positive growth. The limited nutrient supply in this phase of the response brings about a constant relation between fat and lean over a range of growth rates. The minimum 

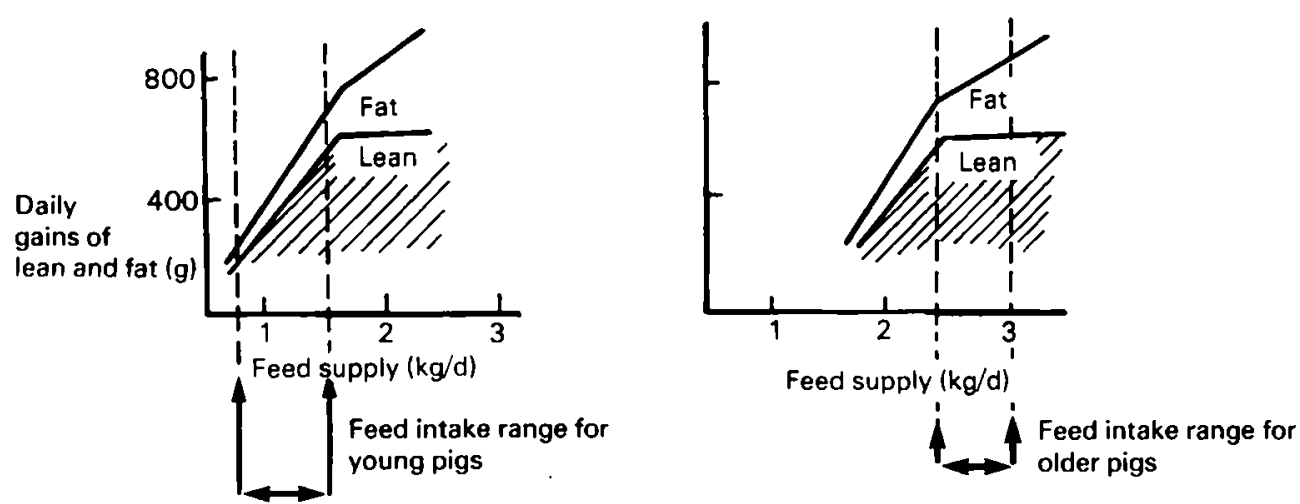

Fig. 2. Growth responses of lean and fat to increasing supply of feed.

fat:lean value is thus an important determinant of body composition for much of the life of the growing animal, and appears to be characteristic of sex and breed type (being lower for males and improved strains). Fatty tissue growth above this minimum can only be achieved when food supply is increased such as to exceed the needs for maintenance, maximum potential rate of daily lean tissue growth rate, and the minimum balance of fat in normal gain. There is little evidence that maximum lean tissue growth rate is either age- or weight-dependent; given adequate feed intake, potential rates appear to be as readily attainable early in life as later. It is self-evident that very young pigs may fail to reach their potential lean gains on account of limited appetites. However, it is becoming apparent that appetite in pigs of $5^{-20} \mathrm{~kg}$ has, in general, been considerably underestimated, and pigs encouraged to consume high levels of feed intake at this time have been found consistently to show linear responses in growth rate. Feed supply may be said to be unlimiting when the plateau for daily lean tissue growth rate is reached, and a concomitant increase is observed in fatty tissue gains as the excess energy is diverted to lipid anabolism. In young pigs of $5-40 \mathrm{~kg}$, or so, the physical bounds of appetite usually restrict food supply to the nutritionally-limiting range, whilst above $40 \mathrm{~kg}$ this is no longer the case. Avoidance of fattening may be achieved by restricting the feed supply in a way that moves it back into the nutritionally-limiting phase. (A reduction in fatness below the minimum stated for normal growth would require a severe restriction to bring about fat catabolism.) Pigs with limited appetites may never be able to eat enough to fatten before slaughter weight is attained. The plateau for daily lean tissue growth rate is dependent on sex and strain of pig, being greater for entire males and improved types. The consequence is for the positive and linear response of lean growth to continue to higher levels of feed intake and to allow greater food consumption without fattening.

\section{Negative growth}

Simultaneous lipid catabolism and protein anabolism is a feature of growth under nutritional stress. Within the bounds of the linear response to feed supply, 


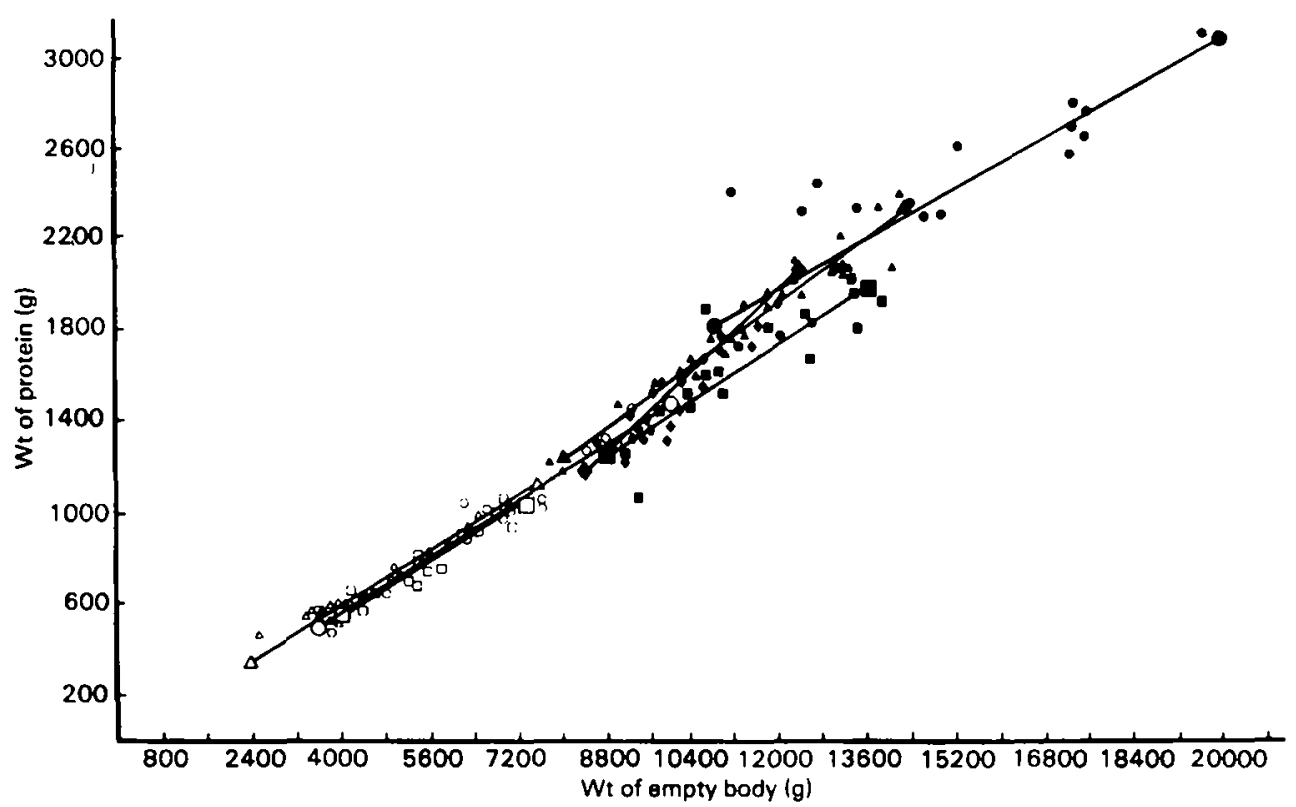

Fig. 3. Protein content of young pigs. (O), Expt I (28 d, at weaning); ( $\square$ ), Expt 2 (2I d, at weaning); $(\triangle)$, Expt 3 (21 d, 7 d post weaning); (O), Expt I (55 d); (U), Expt 2 (53 d); ( $\Delta$ ), Expt 3 (42 d); ( $)$, Expt 4 (42d).

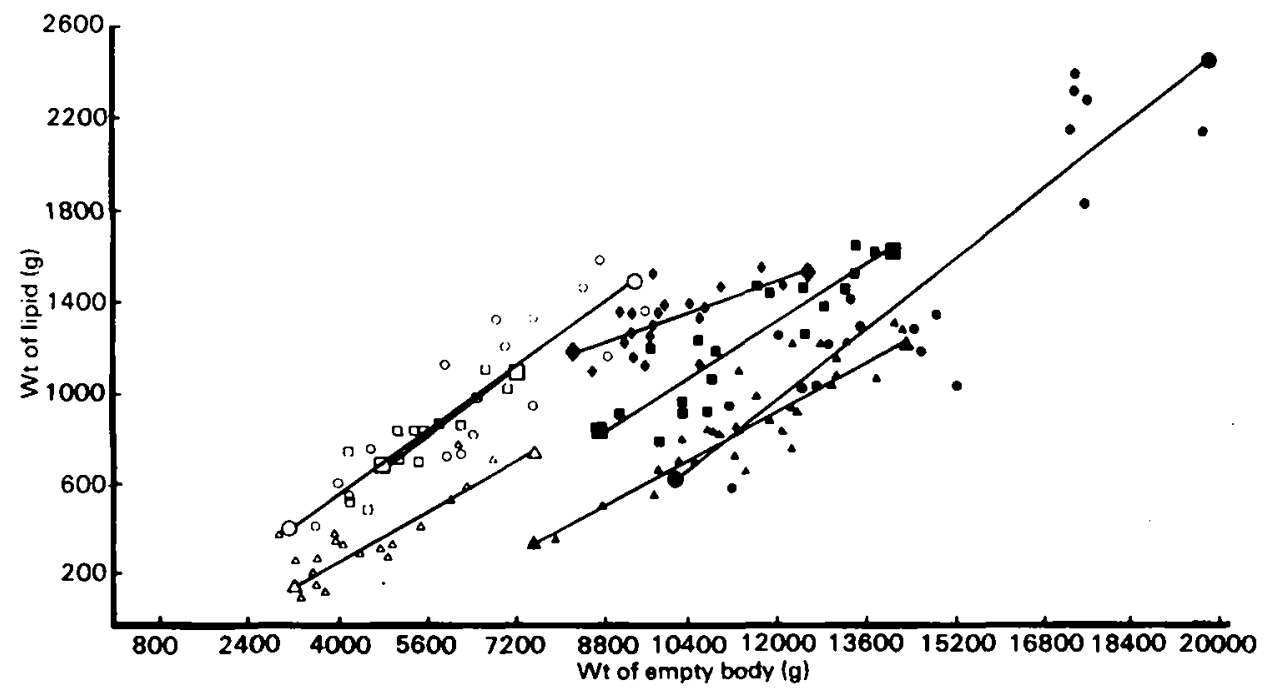

Fig. 4. Lipid content of the body of young pigs. (O), Expt I (28 d, at weaning); ( $\square$ ), Expt 2 (2 I d, at weaning); $(\Delta)$, Expt 3 (2I d, 7 d post weaning); (O), Expt 1 (55 d); (日), Expt 2 (53 d); ( $\Delta$ ), Expt 3 $(42 \mathrm{~d}) ;(\theta)$, Expt $4(42 \mathrm{~d})$.

normal growth for pigs of average sex and type may be quite well described over the whole of the growth period as comprising $15 \%$ protein and $15 \%$ lipid, with $67 \%$ water. Whittemore et al. (1978) showed how, in young pigs, the percentage of fat could be halved in $7 \mathrm{~d}$, the live weight remain constant, and the difference be made up with an increase in water content to $73 \%$. The remarkable intransigency 
of the protein content of the empty body through both positive and negative growth is shown in Fig. 3, while Fig. 4 demonstrates both the dramatic reduction in fat and the parallelism of the subsequent response, indicating the constancy of the proportion of fat in the gains of these young animals. While the pigs lost lipid but not protein, subsequent gains comprised both tissues in approximately equal proportion. A more rigorous examination of negative growth in young pigs (Whittemore et al. 1981) allowed the derivation of the regressions:

$$
\begin{aligned}
& W G(g / d)=0.56 \text { EBWG }+53 \\
& \text { LG }(g / d)=0.29 E B W G-56 \\
& \text { PG }(g / d)=0.15 E B G-4
\end{aligned}
$$

where WG, LG and PG are the water, lipid and protein gains respectively. At zero EBWG, WG counterbalanced lipid losses, and PG was insignificant. Lipid losses continued until the total body gains rose to about $200 \mathrm{~g}$ daily, while PG simultaneously increased from -4 to $+28 \mathrm{~g}$. At $100 \mathrm{~g}$ daily total body gains, $27 \mathrm{~g}$ lipid were lost and I $g$ protein were deposited.

The possibility of compensatory growth was examined by Tullis (1982) who failed to demonstrate the phenomenon with respect to EBWG, but did show short-term enhancement of nitrogen retention following deprivation. Recently, C. Stamataris (unpublished results) has pointed to the possibility that compensation may occur during the early part of the re-alimentation phase, but may primarily be in the form of gut-fill, lipid, and protein in the alimentary tract and associated organs. In any event, interrupted or slowed growth is costly, and production systems would gain by increasing the feed intake and growth rates of pigs, especially in early life.

\section{Production needs}

The early identification of causes of variation in fatness in pigs has resulted in the breeding of improved types with high maximum daily lean-tissue-growth-rate potentials, low minimum fat ratios in nutrient-limited growth and restricted appetites. Specification of nutrient requirements by the factorial method (Agricultural Research Council, 1981) allows exact nutrient supply and avoids the possibility of fatness through faulty diet specification, while, where necessary, feed restriction can further control fatness. The minimum amount of fat commensurate with meat quality and consumer acceptability can therefore readily be obtained. The ever-narrowing range of fatness that defines the limits of consumer needs is now creating problems for producers who have to cope with natural biological variation in weight and fatness, whilst simultaneously satisfying targets of diminishing size for both characters. Further reductions in biological variation are most likely to come from improving the nutrition and management of the pig in the early growth phase where there is currently the greatest gap between achieved performance and biological potential. 


\section{REFERENCES}

Agricultural Research Council. (1981). The Nutrient Requirements of Pigs. Farnham Royal: Commonwealth Agricultural Bureaux.

Henderson, R. (1982). Comparative growth and body composition of index selected and control lines of Large White pigs. PhD Thesis, University of Edinburgh.

Kotarbinska, M. (1969). Badania nad Przemiana Energii u Rosuacych swin. Wroclaw: Instytut Zootechniki.

McMeekan, C. P. (1940). Journal of Agricultural Science 30, 276-343.

Spray, C. M. \& Widdowson, R. A. (1950). British foumal of Nutrition 4, 332-360.

Tullis, J. B. (1982). Protein growth in pigs. PhD Thesis, University of Edinburgh.

Whittemore, C. T., Aumaitre, A. \& Williams, I. H. (1978). fournal of Agricultural Science, Cambridge 91, $681-692$.

Whittemore, C. T., Taylor, H. M., Henderson, R., Wood, J. D. \& Brock, D. C. (1981). Animal Production 32, 203-210.

Wood, J. D. (1984). In Fats in Animal Nutrition pp. 407-435 [J. Wiseman, editor]. London: Butterworths.

Wood, J. D., Enser, M. \& Fisher, A. V. (1983). Proceedings of the 29th European Meeting of Meat Research Workers 2, $\mathrm{D}_{3} \mathrm{1}, 6 \mathrm{1}_{4}-620$.

Wood, J. D., Jones, R. C. D., Bayntun, J. A. \& Dransfield, E. (1985). Animal Production 40, $4^{81} \mathrm{I}-488$. 